\title{
Driving Simulator Validity of Driving Behavior in Work Zones
}

\author{
Yanning Zhang, ${ }^{1}$ Zhongyin Guo $\mathbb{D}^{1}{ }^{1}$ and Zhi Sun ${ }^{2,3}$ \\ ${ }^{1}$ Key Laboratory of Road and Traffic Engineering of the Ministry of Education, Tongji University, Shanghai 201804, China \\ ${ }^{2}$ China State Construction Shandong Investment Corporation, Jinan 250101, China \\ ${ }^{3}$ China State Construction Infrastructure Corporation, Beijing 100044, China
}

Correspondence should be addressed to Zhongyin Guo; zhongyin@tongji.edu.cn

Received 15 February 2020; Accepted 25 May 2020; Published 9 June 2020

Academic Editor: Cheol Oh

Copyright (c) 2020 Yanning Zhang et al. This is an open access article distributed under the Creative Commons Attribution License, which permits unrestricted use, distribution, and reproduction in any medium, provided the original work is properly cited.

\begin{abstract}
Driving simulation is an efficient, safe, and data-collection-friendly method to examine driving behavior in a controlled environment. However, the validity of a driving simulator is inconsistent when the type of the driving simulator or the driving scenario is different. The purpose of this research is to verify driving simulator validity in driving behavior research in work zones. A field experiment and a corresponding simulation experiment were conducted to collect behavioral data. Indicators such as speed, car-following distance, and reaction delay time were chosen to examine the absolute and relative validity of the driving simulator. In particular, a survival analysis method was proposed in this research to examine the validity of reaction delay time. The result indicates the following: (1) most indicators are valid in driving behavior research in the work zone. For example, spot speed, car-following distance, headway, and reaction delay time show absolute validity. (2) Standard deviation of the car-following distance shows relative validity. Consistent with previous researches, some driving behaviors appear to be more aggressive in the simulation environment.
\end{abstract}

\section{Introduction}

Driving simulation has been increasingly popular in transportation research because of its efficiency, safety, and controllability. By using driving simulation, researchers can design a specific driving scenario, conduct experiments in a closed and safe environment, and collect precise and diverse data through sensors. These advantages are prominent when driving behavior occurs in a scenario that is dangerous or difficult to reproduce.

For simulation experiments, simulator validity is an unavoidable issue; it refers to the ability of a simulator to reproduce real-world driving accurately [1]. However, simulator validity is inconsistent when the type of the driving simulator or the driving scenario is different, and there is no standardized method for assessing simulator validity [1]. Therefore, it is appropriate to verify the validity of the apparatus before conducting a simulation experiment.

Many driving scenarios need to be verified; one of them is driving in work zones. Work zones are considered to have a negative impact on traffic safety and mobility because of lane closure and lower speed limits [2]. The vehicle speed at the beginning of the work zone always exceeds the speed limit, and the deceleration before the work zone is high [3]. At the same time, the risk of rear-end crash is higher than in nonwork zones [4-6]. It is dangerous to reproduce these driving scenarios in the real world, which makes the driving simulator a perfect tool for relevant researches.

The primary objective of this research is to verify the validity of behavioral research in the work zone. A field experiment and a corresponding simulation experiment were conducted here to collect behavioral data. Indicators were chosen to identify simulator validity. Moreover, a survival analysis method was proposed here to analyze the validity of reaction delay time.

The arrangement of this paper is presented as follows. Section 2 is an overview of the current literature. In the next section, the apparatus, participants, and experiment process are provided. Section 4 is the definition of indicators and the survival analysis method. The rest of the sections are the results, discussion, and conclusion. 


\section{Literature Review}

Driving simulator validity is a prerequisite of simulationbased research. There are different classifications of simulator validity. One of the widely used simulator validity is absolute-relative validity. Absolute validity indicates that no significant differences between real-world driving and simulated driving. Relative validity indicates that simulated driving shows the same patterns as real-world driving. However, there are a limited number of research studies that validate a driving simulator by directly comparing simulated and real driving [1]. In these studies, statistical tests are a common method to verify absolute validity. In the meantime, direct comparison and regression models are methods to verify relative validity. Tornros [7] used the Tukey test to verify the absolute validity of speed behavior and lateral behavior in the tunnel driving. Helland et al. [8] and Meuleners and Fraser [9] used the paired sample $t$-test to verify the absolute validity in drunk driving and driving errors, respectively. ANOVA was used to identify the significant difference between real driving and simulated driving, too [10-12]. As for relative validity, Helland et al. [8] used the linear mixed model to verify the relative validity of drunk driving, while Riener [13] verified the relative validity of drivers' reaction delay time by direct comparison.

Data collected from real-world driving and simulated driving are the foundation of driving simulator validity verification. These data always presented in the form of behavioral indicators. Therefore, driving simulator validation research studies can be classified by the type of indicator. Common types of behavioral data are speed $[11,14]$, lateral position $[10,15]$, lane-changing behavior [16-18], driving errors [9], and others [19]. It is worth noting that validation research for car-following behavior is rarely mentioned in the review of simulator validation studies $[1,20]$. In the above cases, indicators are related to the research topic. For example, Branzi [14] used the average speed for speed behavior research. Davenne [16] used inappropriate line crossing time, self-fatigue, and sleepiness for lane-changing behavior and driving fatigue research. Meuleners and Fraser [9] studied driving error with mirror checking, four-direction observations, the speed at interactions, obeying traffic lights, and obeying stop signs.

Speed behavior [21-23] and rear-end-crash-related behavior [6, 24-30] (merging behavior and car-following behavior) have been a primary concern of researchers because of the traffic feature of work zones. Besides naturalistic driving and field experiments, self-report and driving simulation are also used in the research studies for data collection. Debnath [21] compared self-nominated speeds and actual speeds in work zones, finding that participants generally underestimate the speed in work zones. Domenichini [22] conducted a simulation experiment and found that drivers always exceed the speed limit of work zones. These research studies used behavioral indicators to describe driving behaviors. Paolo and Sar [3] used spot speed and deceleration for speed behavior research in work zones. Lochrane et al. [27] used car-following distance and relative speed for car-following behavior research.
The existing studies show that driving simulators have been used in driving behavior research. Some validation research studies corresponding to the particular driving scenario have been proposed. However, there is a gap in simulator validity research for driving in work zones. In particular, simulator validity research for car-following behavior. The validity verification method is not standardized; the direct comparison is still a common method to verify relative validity. This research examines the simulator validity of driving in work zones, including the free-flow scenario and car-following scenario. Statistical methods and regression models are proposed here for validity verification. Especially, a survival analysis method is proposed here for time-event data like reaction delay time.

\section{Experimental}

3.1. Apparatus. A field experiment and a simulation experiment were conducted in this research. The field experiment data were collected by instrumented vehicles. The on-board data processing system integrated the data and output it at a frequency of $10 \mathrm{~Hz}$. The driving simulator used in the simulation experiment consisted of an eight degreeof-freedom motion system, a fully instrumented vehicle, and a high-fidelity visual system. The motion system provided drivers with driving force feedback. Sensors of the instrumented vehicle collected data while driving. The visual system consisted of five simulation projectors; the projectors produced a view of horizontal 250 degrees and vertical 40 degrees. LCD monitors provided a view of rearview mirrors. SCANeR $^{\mathrm{TM}}$ software was used to edit driving scenarios and integrate experiment data. Simulation data were also output at a frequency of $10 \mathrm{~Hz}$. The apparatuses are shown in Figure 1 .

3.2. Participants. The recruitment method of this research followed the method in Davenne et al.'s research [16]. 36 healthy men were recruited; all of them held a valid driving license and had daily-driving experience for at least one year. There were 20 drivers for the field experiment (mean age $\pm \mathrm{SD}=25.4 \pm 3.5$ years; mean driving age $\pm \mathrm{SD}=3.3 \pm 1.5$ years) and 16 matched drivers for the simulation experiment (mean age $\pm \mathrm{SD}=25.6 \pm 2.4$ years; mean driving age $\pm \mathrm{SD}=3.7 \pm 1.1$ years). A pretest was provided to ensure every participant is familiar with the requirement of experiments and the operation method of apparatus.

3.3. Experiment Tasks. The free-flow scenario and car-following scenario were chosen in this research. These scenarios were the same both in the field and simulation experiments. The field experiment was conducted on a twoway four-lane highway in Shandong Province, China. The length of the test section was $10 \mathrm{~km}$, and the speed limit of the test section was $100 \mathrm{~km} / \mathrm{h}$. The road section in the driving simulator is shown in Figure 2. The speed limit sign and other essential preinformation signs were installed in the simulation experiment to reproduce the road section in the field experiment. To verify the relative validity, $2 \times \mathrm{N}$ design 


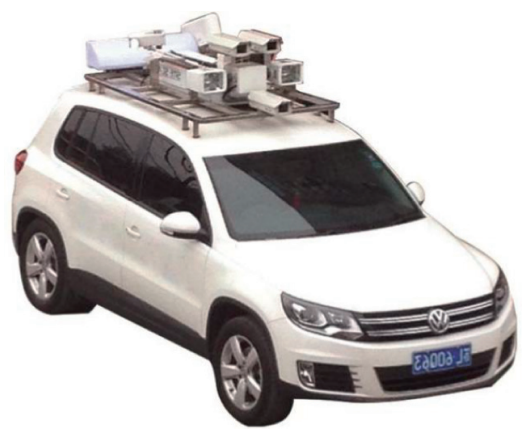

(a)

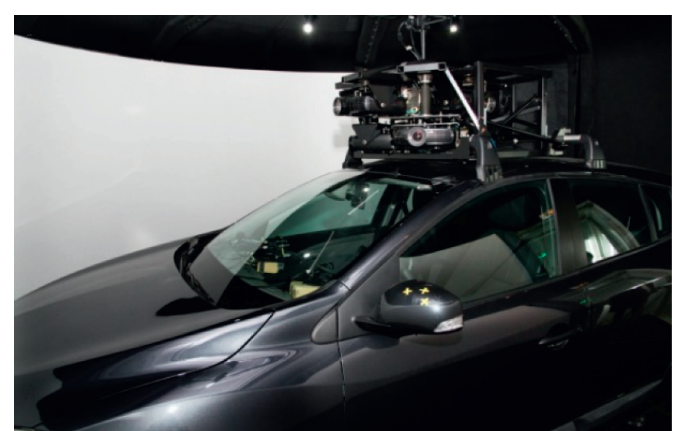

(b)

FIgURE 1: Experimental apparatuses: (a) the instrumented vehicle; (b) the driving simulator.

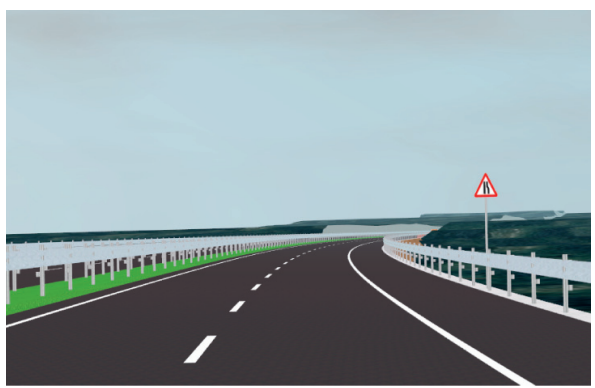

(a)

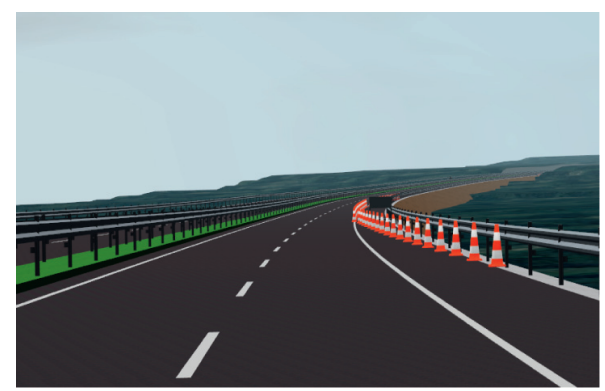

(b)

FIgURE 2: Road section in the driving simulator.

with driving environments and other factors were employed in the study.

For the free-flow scenario, the factor was the lane closure type. Two tests were contained in the free-flow scenario; one of them closed the passing lane, and another closed the emergency lane. There were four work zones in each test.

For the car-following scenario, the factor was the leading vehicle's speed. The car-following scenario was designed as follows to reproduce the rapid deceleration at the beginning of work zones [3] and acceleration at the end of work zones. The driver of the following vehicle was required to follow the leading vehicle and keep it in the same lane for the whole test. The driver of the leading vehicle kept driving at a stable speed before accelerating or decelerating. The upper and lower bounds of the leading vehicle's speed were $40 \mathrm{~km} / \mathrm{h}$ and $80 \mathrm{~km} / \mathrm{h}$; the gradient of speed changing was $20 \mathrm{~km} / \mathrm{h}$.

\section{Indicators and Validation Methods}

4.1. Driving Behavior Indicators. Free-flow indicators are spot speed, speed reduction, and speed reduction rate. The spots include the beginning of deceleration (BD) and the end of deceleration (ED). Speed reduction rate refers to the deceleration at the beginning of the work zone. The calculation method is shown in the following equation:

$$
\mathrm{SRR}=\frac{v_{\mathrm{BD}}-v_{\mathrm{ED}}}{t_{\mathrm{D}}},
$$

where SRR is the speed reduction rate. $v_{\mathrm{BD}}$ is the speed at $\mathrm{BD}$. $v_{\mathrm{ED}}$ is the speed at ED. $t_{\mathrm{D}}$ is the time for the vehicle to drive from $\mathrm{BD}$ to $\mathrm{ED}$. The algorithm to identify the speed change point follows the method in Zhang's research [31].

Car-following indicators include car-following distance (average and standard deviations when speed is stable), headway (average and standard deviations when speed is stable), and reaction delay time. The standard deviation of the car-following distance represents the stability of carfollowing behavior. Define $\mathrm{A}$ as the acceleration/deceleration point of the leading vehicle and $\mathrm{B}$ as the acceleration/ deceleration point of the following vehicle. The time interval between $\mathrm{A}$ and $\mathrm{B}$ is regarded as the reaction delay time.

4.2. Survival Analysis Method. The validation methods for nontime data are the Wilcoxon test and linear regression. In the meantime, a survival analysis method is proposed for time-event data such as reaction delay time. Survival analysis is a collection of statistical procedures for data analysis for which the outcome variable of interest is time until an event occurs [32]. According to the basic concept of survival analysis, the key elements of survival analysis include events, survival time $t$, the consequence of event (failure) $\delta$, survivor functions of the event $S(t)$, and hazard function of the event $h(t)$.

In this study, an event refers to the following vehicle's response to the leading vehicle's speed change. Survival time is the reaction delay time. An event will be referred to as a failure if the following vehicle does not respond to the leading vehicle's speed change or the reaction delay time exceed the threshold. $S(t)$ represents the probability that the 
survival time (reaction delay time) $T$ exceeds the specified time $t$. Survivor function is a basic component of the survival analysis, and it obtains survival probabilities for different values of $t$, summarizing key information from survival data [32]. A nonparametric method called the Kaplan-Meier method is used in this study to estimate $S(t)$. The formula of the Kaplan-Meier method is shown in the following equations:

$$
\widehat{S}\left(t_{(j)}\right)=\widehat{S}\left(t_{(j-1)}\right) \times \widehat{P}\left(T>t_{(j)} \mid T \geq t_{(j)}\right) .
$$

Iterating equation (2), we have the following:

$$
\widehat{S}\left(t_{(j)}\right)=\prod_{i=1}^{j} \widehat{P}\left(T>t_{(i)} \mid T \geq t_{(j)}\right) .
$$

Data used for the Kaplan-Meier method is arranged in the ascending order of reaction delay time. $t_{(j)}$ is the $j$-th shortest reaction delay time. $\widehat{S}\left(t_{(j)}\right)$ is the estimation of $S(t)$ at time $t_{(j)}$. $\widehat{P}\left(T>t_{(j)} \mid T \geq t_{(j)}\right)$ is the probability that $T$ is larger than $t_{(j)}$ when reaction delay $T$ is larger or equal to $t_{(j)}$. $\widehat{S}\left(t_{(j)}\right)$ is a step function.

Hazard function represents the instantaneous potential per unit time for the event to occur, under the premise that the following vehicle has not reacted to the change at time $t$. Instead of focusing on the continuity of the event, the hazard function focuses on the failure of the event. The hazard function is also called the conditional failure rate, and it is a regression model for survival analysis. The formula of hazard function $h(t)$ is shown in the following equation:

$$
h(t)=\lim _{\Delta t \longrightarrow 0} \frac{P(t \leq T<t+\Delta t \mid T \geq t)}{\Delta t} .
$$

The proportional hazards model (Cox model) is used to estimate $h(t)$. The formula of Cox model is shown in the following equation:

$$
h\left(t_{1}\right)=h_{0}(t) \exp \left[\sum_{i=1}^{n} \beta_{i} X_{i}\right],
$$

where $X$ is the vector of independent variables. In most cases, $X$ is a discrete variable. $\beta_{i}$ is the coefficient of $X_{i} . h_{0}(t)$ is the nonparametric part of the Cox model, and it represents the baseline version of the hazard function.

For reaction delay time, the absolute validity is verified by comparing the difference of $S(t)$ between real-world driving and simulated driving. A chi-square test named LogRank test is used in this research. The relative validity is verified by comparing the coefficients of the Cox model.

\section{Results}

\subsection{Free-Flow Validation}

5.1.1. Spot Speed. The statistical result of spot speed is shown in Figures 3(a) and 3(b). For the beginning of deceleration, spot speeds in the simulation experiment are higher than in the field experiment (passing lane $=6.25 \mathrm{~km} / \mathrm{h}$, emergency lane $=3.63 \mathrm{~km} / \mathrm{h}$ ). Driving environments significantly affect spot speed when the passing lane is closed $(p=0.0289)$; driving environments do not affect spot speed when the emergency lane is closed $(p=0.1397)$. Regarding lane closure type as the independent variable (passing lane $=0$, emergency lane $=1$ ), linear regression results show that lane closure type has the same effect for real-world driving $(\beta=5.91, \quad p=0.0164)$ and simulated driving $(\beta=3.29$, $p=0.1370)$. However, the coefficient for the simulation model is not significant.

For the end of deceleration, spot speeds in the simulation experiment are lower than in the field experiment (passing lane $=2.71 \mathrm{~km} / \mathrm{h}$, emergency lane $=2.79 \mathrm{~km} / \mathrm{h}$ ). However, driving environments have no significant effect on spot speed regardless of the lane closure type (passing lane: $p=0.2209$; emergency lane: $p=0.2290$ ). Linear regression results show that the lane closure type has the same effect for real-world driving $(\beta=-7.30, p=0.0056)$ and simulated driving $(\beta=-7.22, p=0.0139)$. Except for one spot (BD, passing lane), the result shows strong evidence of absolute validity.

5.1.2. Speed Reduction. The statistical result of speed reduction is shown in Figure 3(c). Speed reductions in the simulation experiment are higher than in the field experiment (passing lane $=8.96 \mathrm{~km} / \mathrm{h}$, emergency lane $=6.42 \mathrm{~km} /$ h). Driving environments have a significant effect on speed reduction (passing lane: $p=0.0001$; emergency lane: $p=0.0002)$. Linear regression results show that the lane closure type has the same effect for real-world driving $(\beta=1.39, \quad p=0.3270)$ and simulated driving $(\beta=3.93$, $p=0.0807)$. However, the coefficients of both driving environments are not significant. The result can be a sign of lacking simulator validity.

5.1.3. Speed Reduction Rate. The statistical result of the speed reduction rate is shown in Figure 3(d). Speed reduction rates in the simulation experiment are higher than in the field experiment (passing lane $=0.51 \mathrm{~m} / \mathrm{s}^{2}$, emergency lane $=0.29 \mathrm{~m} / \mathrm{s}^{2}$ ). Driving environments have a significant effect on the speed reduction rate (passing lane: $p<0.0001$; emergency lane: $p<0.0001$ ). Linear regression results show that the lane closure type has the same effect for real-world driving $(\beta=-0.0070, p=0.8020)$ and simulated driving $(\beta=-0.2298, p=0.0196)$. The coefficient for the real-world model is not significant. The result indicates that the speed reduction rate shows no simulator validity.

\subsection{Car-Following Validation}

5.2.1. Car-Following Distance. The statistical result of carfollowing distance is shown in Figures 4(a) and 4(b). For the average of the car-following distance, there is no significant difference between field experiment and simulation experiment $(40 \mathrm{~km} / \mathrm{h}: p=0.5318 ; 60 \mathrm{~km} / \mathrm{h}: p=0.6144 ; 80 \mathrm{~km} / \mathrm{h}$ : $p=0.8845)$. Leading vehicle's speed has the same effect for real-world driving $(\beta=1.09, p<0.0001)$ and simulated driving $(\beta=0.91, p<0.0001)$. The average of the car-following distance shows absolute validity. 

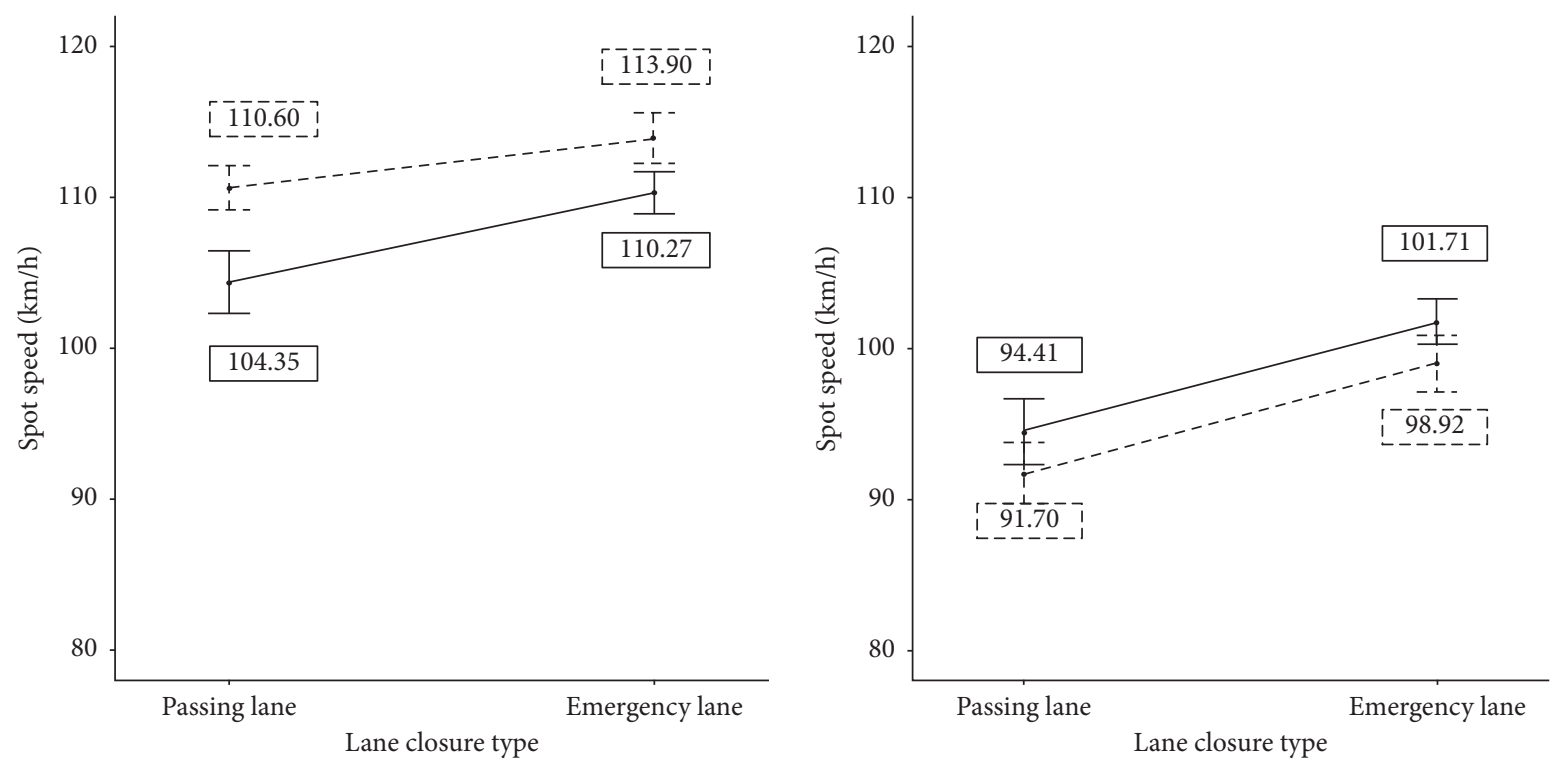

Driving environment

— Real world

- - Simulated

(a)

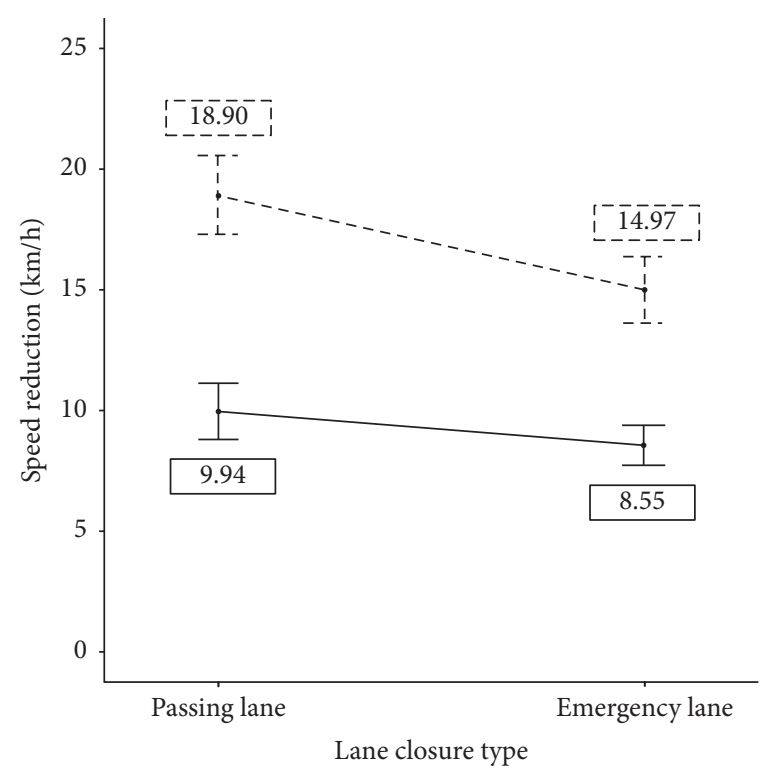

Driving environment

— Real world

- - - Simulated

(b)

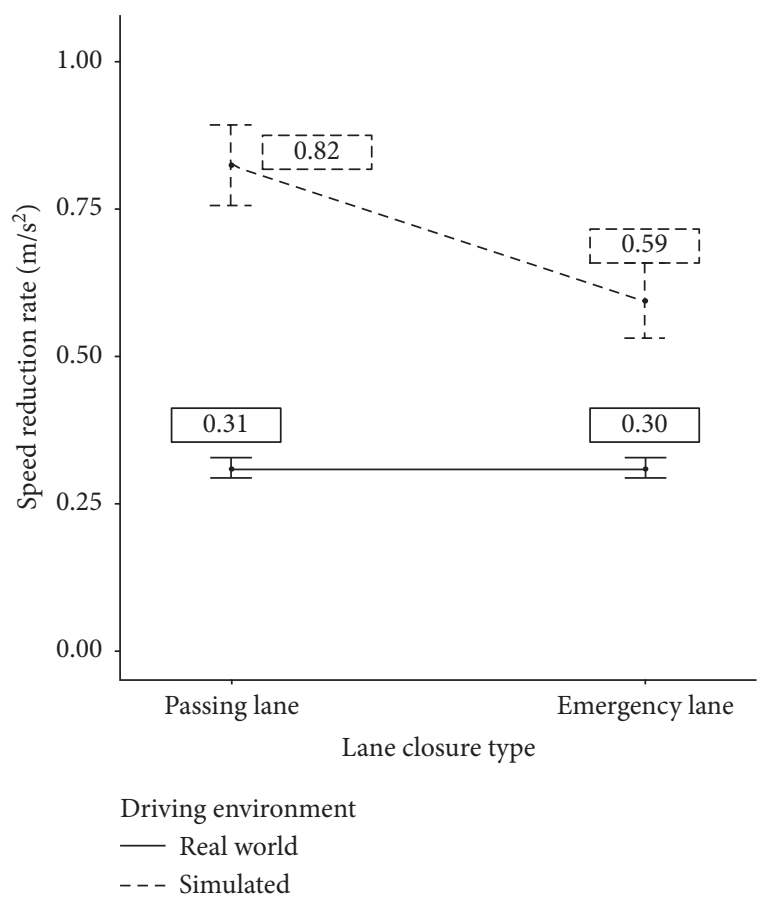

(d)

FIGURE 3: Statistic results of free-flow indicators: (a) spot speed at the beginning of deceleration; (b) spot speed at the end of deceleration; (c) speed reduction; (d) speed reduction rate. The error bars represent the standard deviation of indicators.

For the standard deviation of the car-following distance, the values in the simulation experiment are higher than in the field experiment $(40 \mathrm{~km} / \mathrm{h}: 0.39 \mathrm{~m} ; 60 \mathrm{~km} / \mathrm{h}: 1.79 \mathrm{~m}$; $80 \mathrm{~km} / \mathrm{h}: 3.93 \mathrm{~m}$ ). Driving environments have a significant effect on the indicator $(40 \mathrm{~km} / \mathrm{h}: \quad p=0.0009 ; 60 \mathrm{~km} / \mathrm{h}$ : $p=0.0059 ; 80 \mathrm{~km} / \mathrm{h}: p=0.0136)$. Leading vehicle's speed has the same effect for real-world driving $(\beta=0.06$, $p=0.0078)$ and simulated driving $(\beta=0.12, p<0.0001)$. The result shows the relative validity of the indicator.

5.2.2. Headway. The statistical result of the headway is shown in Figures 4(c) and 4(d). For the average of the headway, there is no significant difference between field 

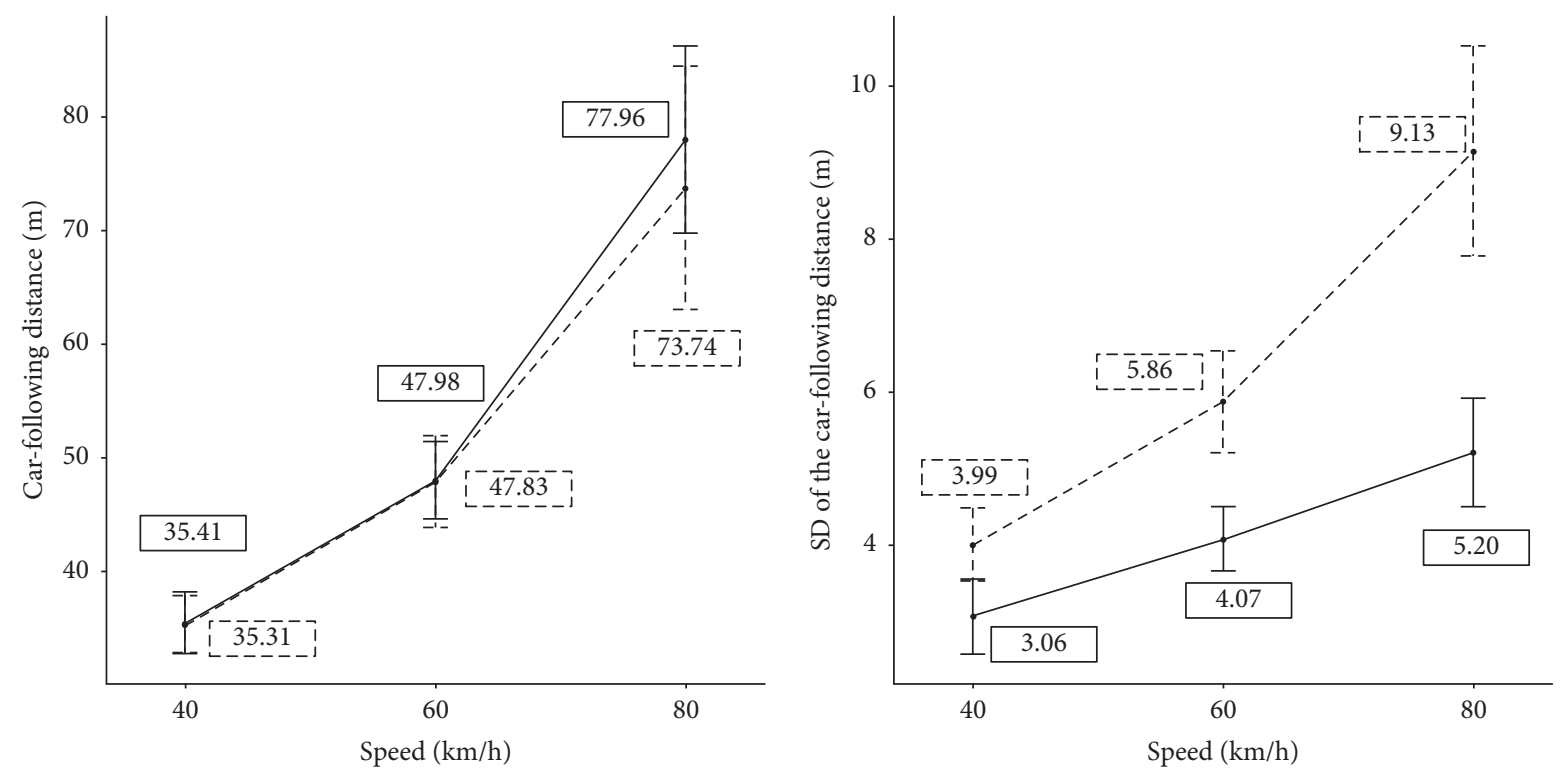

Driving environment

- Real world

- - - Simulated

(a)

Driving environment

— Real world

- - - Simulated

(b)
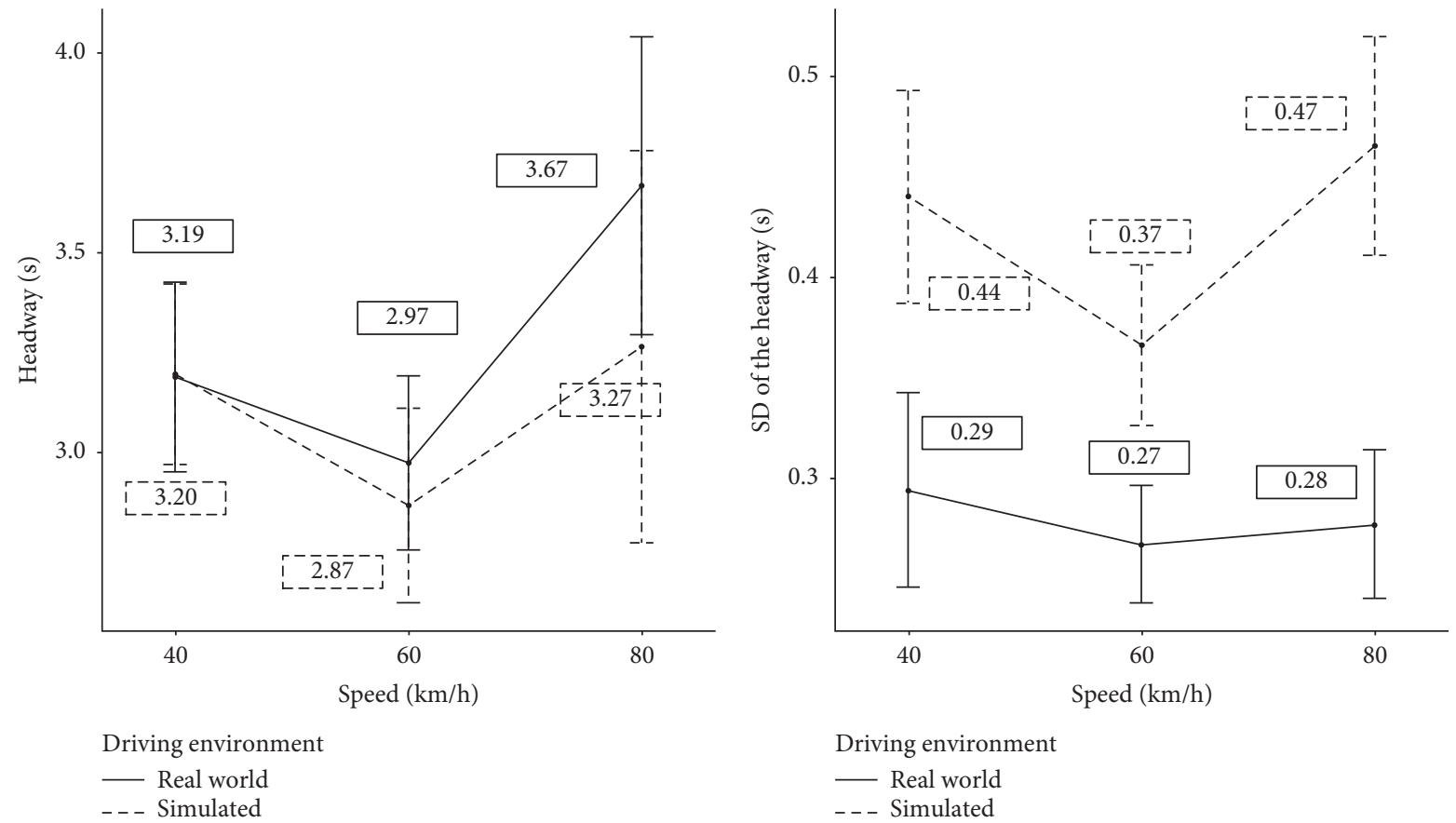

(c)

(d)

FIGURE 4: Statistic results of nontime car-following indicators: (a) car-following distance; (b) standard deviation of the car-following distance; (c) headway; (d) standard deviation of the headway. The error bars represent the standard deviation of indicators.

experiment and simulation experiment $(40 \mathrm{~km} / \mathrm{h}$ : $p=0.8668 ; 60 \mathrm{~km} / \mathrm{h}: \quad p=0.4406 ; 80 \mathrm{~km} / \mathrm{h}: \quad p=0.7996)$. Leading vehicle's speed affects headway in the same pattern. The average of the headway shows absolute validity.

For the standard deviation of the headway, the values in the simulation experiment are higher than in the field experiment $(40 \mathrm{~km} / \mathrm{h}: 0.15 \mathrm{~s} ; 60 \mathrm{~km} / \mathrm{h}: 0.10 \mathrm{~s} ; 80 \mathrm{~km} / \mathrm{h}: 0.19 \mathrm{~s})$. Driving environments have a significant effect on the indicator $(40 \mathrm{~km} /$ h: $p<0.0001 ; 60 \mathrm{~km} / \mathrm{h}: p=0.0065 ; 80 \mathrm{~km} / \mathrm{h}: p=0.0049)$. Figure 4(d) shows that the relationship between the leading vehicle's speed and the indicator is not linear. ANOVA result shows that the leading vehicle's speed $(p=0.5987)$ and the interaction $(p=0.8927)$ do not affect the indicator. Therefore the indicator shows no simulator validity. 

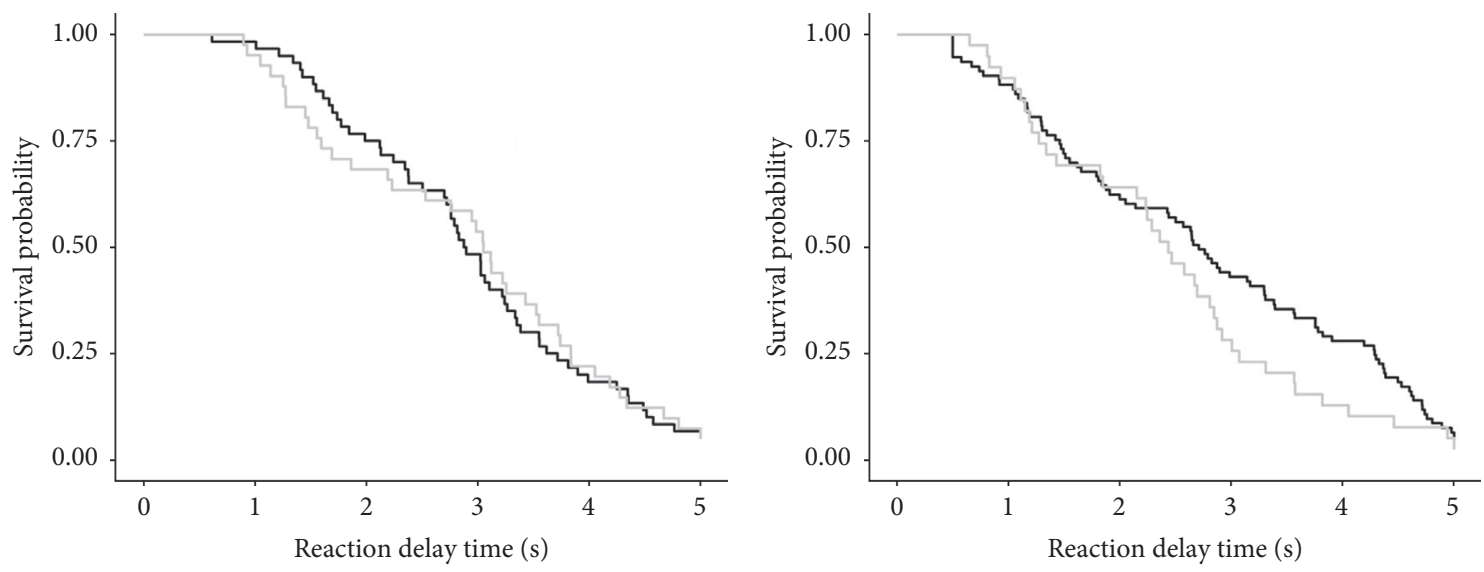

$$
\begin{aligned}
& \text { Driving environment } \\
& - \text { Real world } \\
& \text { Simulated }
\end{aligned}
$$

(a)

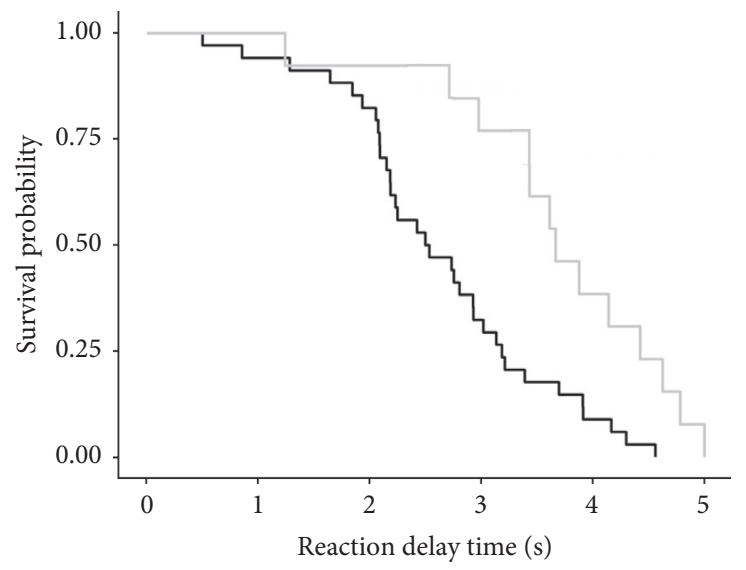

Driving environment

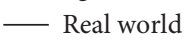

_ Simulated

(c)

\section{Driving environment \\ — Real world \\ _ Simulated}

(b)

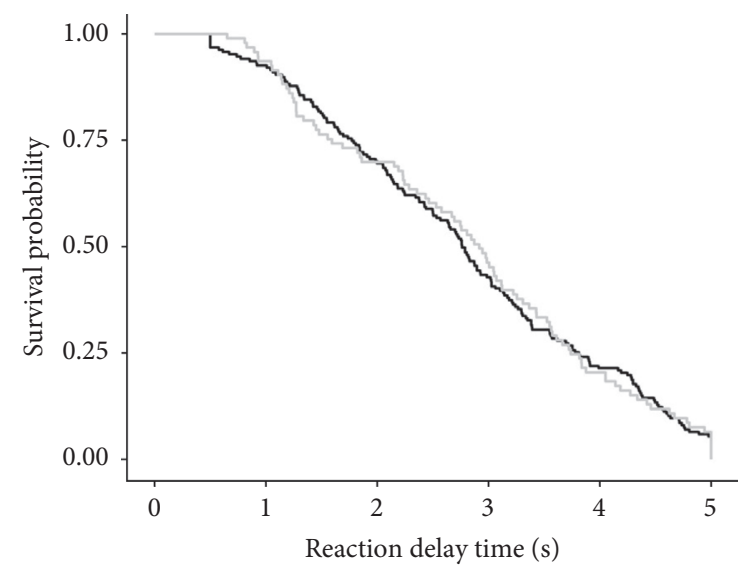

Driving environment

— Real world

Simulated

(d)

FIGURE 5: Results of reaction delay time. The leading vehicle's speed: (a) $40 \mathrm{~km} / \mathrm{h}$; (b) $60 \mathrm{~km} / \mathrm{h}$; (c) $80 \mathrm{~km} / \mathrm{h}$; (d) overall.

5.2.3. Reaction Delay Time. The statistical result of the reaction delay time is shown in Figure 5. The driving environment has no significant effect on the reaction delay time (overall: $p=0.8000 ; \quad 40 \mathrm{~km} / \mathrm{h}: \quad p=0.9000 ; 60 \mathrm{~km} / \mathrm{h}$ : $p=0.2000 ; 80 \mathrm{~km} / \mathrm{h}: p=0.0200)$. Regarding leading vehicle's speed ( 1 for speed $<50 \mathrm{~km} / \mathrm{h} ; 2$ for speed $<70 \mathrm{~km} / \mathrm{h} ; 3$ for speed $\geq 70 \mathrm{~km} / \mathrm{h}$ ), leading vehicle's acceleration ( 0 for acceleration $<0 \mathrm{~m} / \mathrm{s}^{2} ; 1$ for acceleration $\left.\geq 0 \mathrm{~m} / \mathrm{s}^{2}\right)$, and carfollowing distance as the independent variable, the result of Cox model is shown in Table 1 . The result shows that in the real-world model, the leading vehicle's acceleration and carfollowing distance affect reaction delay time significantly. The hazard ratio of the leading vehicle's acceleration is equal to 0.6014 . It means when the leading vehicle is accelerating, the hazard function value of reaction delay decreases by $39.86 \%$ and the reaction delay time is longer. The hazard ratio of relative distance is equal to 0.9911 . It means the hazard function value of reaction delay decreases by $8.55 \%$ for every 10 meters increase in the car-following distance. The reaction delay time is longer. In the simulation model, no independent variable affects the reaction delay time significantly. The survival analysis result shows that the reaction delay time has absolute validity.

\section{Discussion and Conclusion}

This research shows that for driving behavior in work zones, most of the indicators are valid. In the simulation experiment, the speed behavior in the free-flow scenario and the car-following behavior in the car-following scenario are consistent with which in the field experiment. For the speed behavior, vehicle dropping speed rapidly at the beginning of work zones, which is consistent with the study by Paolo and Sar [3]. Taylor et al. [33] pointed out that additional design features like temporary traffic barriers, reduced lane width, and crossover sections may influence vehicle speeds in work 
TABLe 1: Result of the Cox model $\left({ }^{*} p<0.05\right)$.

\begin{tabular}{lcccc}
\hline Environment & Variable & Coefficient & Hazard ratio & $p$ \\
\hline \multirow{3}{*}{ Real-world } & Leading vehicle's speed & 0.1445 & 1.1554 & 0.2376 \\
& Leading vehicle's acceleration & -0.5084 & 0.6014 & 0.9911 \\
\hline \multirow{3}{*}{ Simulation } & Car-following distance & -0.0088 & 0.9881 & $0.0046^{(*)}$ \\
& Leading vehicle's speed & -0.0119 & 0.9674 & 0.9371 \\
& Leading vehicle's acceleration & -0.0330 & 0.9913 & 0.1486 \\
\hline
\end{tabular}

zones. For this research, lane closure is the main feature to affect vehicle speeds. In particular, the vehicle speed is lower and drops more rapidly when the passing lane is closed. As for the car-following behavior, car-following distance has a linear relationship with the leading vehicle's speed. Drivers prefer to keep a longer distance when the speed is higher. This behavior shows strong consistency between the field experiment and simulation experiment. The result of the Cox model indicates that reaction delay time is not a constant but an unfix value related to car-following distance and the leading vehicle's acceleration. This finding is proved by previous research studies [34-37]. Instead of treating the relationship between reaction delay time and independent variables as linear [34-36], this study uses a proportional hazards model to describe the probability distribution of reaction delay time. However, the model result for the simulation experiment is not significant. Perhaps further research is needed to find out the reason.

Past researches reported that driving simulators have relative validity, but do not exactly replicate the driving behavior of the real world [38]. Driving behaviors in the simulation experiment are more aggressive than in the field experiment. For example, vehicle speed in the simulation experiment is higher, and the deceleration at the beginning of the work zone is higher, too. These behaviors can conduct to a high probability of traffic crash [3]. Similar results were reported by previous researches [7, 14, 39-41]. The standard deviation of the car-following distance and standard deviation of the headway are higher in the simulation experiment, which means the car-following process is more stable in real-world driving. The safety of driving simulators may be an explanation of aggressive behaviors. Helland et al. $[8,15]$ reported that the aggressive driving behaviors in the simulation experiment can be explained by an enhanced perception of real danger in real-world driving compared to the simulator. Bella [41] conducted a similar conclusion.

Overall, the simulator validity of driving behaviors in work zones is verified. The speed behavior and car-following behavior in the simulation environment show a similar pattern as which in the real-world environment. A survival analysis method is proposed to replace the direct comparison method for simulator validity verification of the timeevent data. Comparing to linear regression models, the proposed model can describe the probability distribution of reaction delay time. The result of this research can be theoretical support for simulation-based research, especially for driving behavior research in work zones. Consistent with previous researches, some behaviors are more aggressive in the simulation experiment, which needs further research to explain the mechanism.

This study deals with one critical issue of driving behavior research based on the driving simulator. The survival analysis method proposed in the study provides an effective way to verify time-event data. However, this study still has some limitations. First, in the free-flow validation study, the deceleration behavior is presented by spot speed. Although the spot speed can represent the deceleration behavior feature, it still should be noticed that this behavior is continuous. Thus in future research, the driving simulation validation based on speed profile should be discussed. Second, merging behavior or lane-changing behavior also is important in the work zone area $[6,28,29]$. The driving simulator validity of merging behavior will be an interesting topic. It should be mentioned that collecting merging behavior in real-world driving situations is a challenging job; advanced technology and method should be proposed to deal with it.

\section{Data Availability}

The data used to support the findings of this study are available upon request to Yanning Zhang, 1433932_zyn@ tongji.edu.cn.

\section{Conflicts of Interest}

The authors declare that there are no conflicts of interest regarding the publication of this paper.

\section{Acknowledgments}

This research was financially supported by Technology Research and Development Plan of China State Construction Engineering Corporation (CSCEC-2017-Z-20) and the National Natural Science Foundation of China (71673201).

\section{References}

[1] R. A. Wynne, V. Beanland, and P. M. Salmon, "Systematic review of driving simulator validation studies," Safety Science, vol. 117, pp. 138-151, 2019.

[2] A. Z. Abdelmohsen and K. El-Rayes, "Optimizing the planning of highway work zones to maximize safety and mobility," Journal of Management in Engineering, vol. 34, no. 1, Article ID 04017048, 2018.

[3] P. Paolo and D. Sar, "Driving speed behaviour approaching road work zones on two-lane rural roads," Procedia-Social and Behavioral Sciences, vol. 53, pp. 672-681, 2012. 
[4] Y. Qi, R. Srinivasan, H. Teng, and R. Baker, "Analysis of the frequency and severity of rear-end crashes in work zones," Traffic Injury Prevention, vol. 14, no. 1, pp. 61-72, 2013.

[5] C. Silverstein, J. Schorr, and S. H. Hamdar, "Work zones versus nonwork zones: risk factors leading to rear-end and sideswipe collisions," Journal of Transportation Safety \& Security, vol. 8, no. 4, pp. 310-326, 2015.

[6] J. Weng and Q. Meng, "Rear-end crash potential estimation in the work zone merging areas," Journal of Advanced Transportation, vol. 48, no. 3, pp. 238-249, 2014.

[7] J. Törnros, "Driving behaviour in a real and a simulated road tunnel-a validation study," Accident Analysis \& Prevention, vol. 30, no. 4, pp. 497-503, 1998.

[8] A. Helland, G. D. Jenssen, L.-E. Lervåg et al., "Evaluation of measures of impairment in real and simulated driving: results from a randomized, placebo-controlled study," Traffic Injury Prevention, vol. 17, no. 3, pp. 245-250, 2016.

[9] L. Meuleners and M. Fraser, "A validation study of driving errors using a driving simulator," Transportation Research Part F: Traffic Psychology and Behaviour, vol. 29, pp. 14-21, 2015.

[10] D. Hallvig, A. Anund, C. Fors et al., "Sleepy driving on the real road and in the simulator-a comparison," Accident Analysis \& Prevention, vol. 50, pp. 44-50, 2013.

[11] S. T. Godley, T. J. Triggs, and B. N. Fildes, "Driving simulator validation for speed research," Accident Analysis \& Prevention, vol. 34, no. 5, pp. 589-600, 2002.

[12] H. B. Ekanayake, P. Backlund, T. Ziemke, R. Ramberg, K. P. Hewagamage, and M. Lebram, "Comparing expert driving behavior in real world and simulator contexts," International Journal of Computer Games Technology, vol. 2013, pp. 1-14, 2013.

[13] A. Riener, "Simulating on-the-Road behavior using a driving simulator," in Proceedings of Third International Conference on Advances in Computer-Human Interactions, vol. 25-31, IEEE, Saint Maarten, Netherlands Antilles, March 2010.

[14] V. Branzi, L. Domenichini, and F. La Torre, "Drivers' speed behaviour in real and simulated urban roads-a validation study," Transportation Research Part F: Traffic Psychology and Behaviour, vol. 49, pp. 1-17, 2017.

[15] A. Helland, G. D. Jenssen, L. E. Lervag et al., "Comparison of driving simulator performance with real driving after alcohol intake: a randomised, single blind, placebo-controlled, cross-over trial," Accident Analysis \& Prevention, vol. 53, pp. 9-16, 2013.

[16] D. Davenne, R. Lericollais, P. Sagaspe et al., "Reliability of simulator driving tool for evaluation of sleepiness, fatigue and driving performance," Accident Analysis \& Prevention, vol. 45, pp. 677-682, 2012.

[17] A. Daurat, P. Sagaspe, L. Motak et al., "Lorazepam impairs highway driving performance more than heavy alcohol consumption," Accident Analysis \& Prevention, vol. 60, pp. 31-34, 2013.

[18] M. Yun, J. Zhao, J. Zhao, X. Weng, and X. Yang, "Impact of invehicle navigation information on lane-change behavior in urban expressway diverge segments," Accident Analysis \& Prevention, vol. 106, pp. 53-66, 2017.

[19] F. Galante, F. Bracco, C. Chiorri, L. Pariota, L. Biggiero, and G. N. Bifulco, "Erratum to "validity of mental workload measures in a driving simulation environment," Journal of Advanced Transportation, vol. 2018, Article ID 6713745, 1 pages, 2018

[20] E. Blana, Driving Simulator Validation Studies: A Literature Review, Institute of Transport Studies University of Leeds, Leeds, UK, 1996.
[21] A. K. Debnath, R. Blackman, and N. Haworth, "A comparison of self-nominated and actual speeds in work zones," Transportation Research Part F: Traffic Psychology and Behaviour, vol. 35, pp. 213-222, 2015.

[22] L. Domenichini, F. La Torre, V. Branzi, and A. Nocentini, "Speed behaviour in work zone crossovers. A driving simulator study," Accident Analysis \& Prevention, vol. 98, pp. 10-24, 2017.

[23] R. T. Steinbakk, P. Ulleberg, F. Sagberg, K. I. Fostervold, and K. I. Fostervold, "Analysing the influence of visible roadwork activity on drivers' speed choice at work zones using a videobased experiment," Transportation Research Part F: Traffic Psychology and Behaviour, vol. 44, pp. 53-62, 2017.

[24] H. Abdulsattar, A. Mostafizi, and H. Wang, "Surrogate safety assessment of work zone rear-end collisions in a connected vehicle environment: agent-based modeling framework," Journal of Transportation Engineering, Part A: Systems, vol. 144, no. 8, Article ID 04018038, 2018.

[25] Q. Meng and J. Weng, "Evaluation of rear-end crash risk at work zone using work zone traffic data," Accident Analysis \& Prevention, vol. 43, no. 4, pp. 1291-1300, 2011.

[26] J. Weng, S. Xue, Y. Yang, X. Yan, and X. Qu, "In-depth analysis of drivers' merging behavior and rear-end crash risks in work zone merging areas," Accident Analysis \& Prevention, vol. 77, pp. 51-61, 2015.

[27] T. W. P. Lochrane, H. Al-Deek, D. J. Dailey, and C. Krause, "Modeling driver behavior in work and nonwork zones," Transportation Research Record: Journal of the Transportation Research Board, vol. 2490, no. 1, pp. 116-126, 2015.

[28] J. Weng, G. Du, D. Li, and Y. Yu, "Time-varying mixed logit model for vehicle merging behavior in work zone merging areas," Accident Analysis \& Prevention, vol. 117, pp. 328-339, 2018.

[29] J. Weng, G. Li, and Y. Yu, "Time-dependent drivers' merging behavior model in work zone merging areas," Transportation Research Part C: Emerging Technologies, vol. 80, pp. 409-422, 2017.

[30] K. Gao, H. Tu, L. Sun, N. N. Sze, Z. Song, and H. Shi, "Impacts of reduced visibility under hazy weather condition on collision risk and car-following behavior: implications for traffic control and management," International Journal of Sustainable Transportation, vol. 14, pp. 1-8, 2019.

[31] X. Zhang and H. B. Ghulam, "Estimation of driver reaction time from detailed vehicle trajectory data," in Proceedings of the IASTED International Conference on Modelling, Simulation and Optimatization, pp. 574-579, Montreal, Canada, January 2007.

[32] M. Carpenter, "Survival analysis: a self-learning text," Technometrics, vol. 39, no. 2, pp. 228-229, 1997.

[33] D. R. Taylor, S. Muthiah, B. T. Kulakowski, K. M. Kulakowski, and R. J. Mahoney, "Artificial neural network speed profile model for construction work zones on high-speed highways," Journal of Transportation Engineering, vol. 133, no. 3, pp. 198-204, 2007.

[34] A. Khodayari, A. Ghaffari, R. Kazemi, and R. Braunstingl, “A modified car-following model based on a neural network model of the human driver effects," IEEE Transactions on Systems, Man, and Cybernetics-Part A: Systems and Humans, vol. 42, no. 6, pp. 1440-1449, 2012.

[35] H. Ozaki, "Reaction and anticipation in the car-following behavior," in Proceedings of the 13th International Symposium on Traffic and Transportation Theory, vol. 49, no. 6, pp. 349-366, Lyon, France, July 1993.

[36] J. Zheng, K. Suzuki, and M. Fujita, "Car-following behavior with instantaneous driver-vehicle reaction delay: a neural- 
network-based methodology," Transportation Research Part C: Emerging Technologies, vol. 36, pp. 339-351, 2013.

[37] R. Sipahi, F. M. Atay, and S.-I. Niculescu, "Stability of traffic flow behavior with distributed delays modeling the memory effects of the drivers," SIAM Journal on Applied Mathematics, vol. 68, no. 3, pp. 738-759, 2008.

[38] M. Matowicki and O. Přibyl, "Cross-study research on utility and validity of driving simulator for driver behavior analysis," Acta Polytechnica CTU Proceedings, vol. 12, p. 68, 2017.

[39] C. Llorca and H. Farah, "Passing behavior on two-lane roads in real and simulated environments," Transportation Research Record: Journal of the Transportation Research Board, vol. 2556, no. 1, pp. 29-38, 2016.

[40] D. Llopis-Castelló, F. J. Camacho-Torregrosa, J. Marín-Morales, A. M. Pérez-Zuriaga, A. García, and J. F. Dols, "Validation of a low-cost driving simulator based on continuous speed profiles," Transportation Research Record: Journal of the Transportation Research Board, vol. 2602, no. 1, pp. 104-114, 2016.

[41] F. Bella, "Driving simulator for speed research on two-lane rural roads," Accident Analysis \& Prevention, vol. 40, no. 3, pp. 1078-1087, 2008. 